Article

\title{
Evaluating Energy Sustainability Using the Pressure-State-Response and Improved Matter-Element Extension Models: Case Study of China
}

\author{
Shuyu $\mathrm{Li}^{1}$ and Rongrong $\mathrm{Li}^{1,2, *}$ \\ 1 School of Economics and Management, China University of Petroleum (East China), Qingdao 266580, \\ Shandong, China; lishyu026@126.com \\ 2 School of Management \& Economics, Beijing Institute of Technology, Haidian District, Beijing 100081, China \\ * Correspondence: lirr@upc.edu.cn
}

Received: 30 November 2018; Accepted: 2 January 2019; Published: 8 January 2019

\begin{abstract}
Most existing studies on energy sustainability have focused on qualitative research. Few studies have applied quantitative methods, and there has not been a systematic review of energy sustainability. To fill this gap, this study first developed a sustainable energy evaluation index system consisting of 20 indicators across the three dimensions of economy, energy, and environment based on the pressure-state-response (PSR) model. The weights of these indicators were then determined in conjunction with the weighting method. Finally, the matter-element extension method was improved to quantify energy sustainability. The proposed method was applied to evaluate China's energy sustainability status from 2000 to 2015. The results show that China's status continued to improve; however, it remained at a low level. To improve China's energy sustainability, more efforts are needed in the economic, energy, and environmental dimensions.
\end{abstract}

Keywords: energy sustainability indicators; pressure-state-response model; weighting method; Improved matter-element extension model; China

\section{Introduction}

Energy plays a pivotal role in economic development, and also supports the material foundation for a modern economy. Limited energy sources and fast-growing demand has made energy sustainability one of the largest challenges for sustainable development. This situation is even more serious in China. China's per capita energy resources are significantly lower than the world average. For example, the average per capita coal resources of China are only half of the world's average, and the per capita oil and natural gas resources occupy only one-fifteenth of the world's average [1]. Concurrently, China has shifted from a largely agrarian society to an industrial and urbanized society [2]. The development of advanced productive forces mainly depends on energy consumption. A commensurate increase in energy consumption results in increased pollutant emissions. The sharp contradiction between energy resources, economic development, and environmental pollution has increased China's difficulty in achieving energy sustainability. This makes it urgent to study China's evolution and status of energy sustainability to better implement an energy sustainability strategy.

Given this background, using the three dimensions of energy, economy, and environment, we utilized the pressure-state-response (PSR) model to construct a comprehensive index system to evaluate energy sustainability. We mainly used an improved matter-element extension method and combination weighting method to study and evaluate the time-varying state of China's energy sustainability. The goal was to describe the status quo of energy sustainability in China more comprehensively 
and systematically. The study also provides a reference for those studying energy issues in other developing countries.

The rest of this paper is organized as follows. Section 2 presents previous research on this topic. Section 3 presents the methodology and model specifications. Section 4 presents the results. Section 5 is the corresponding discussion. Finally, Section 6 offers conclusions.

\section{Literature Review}

For this literature review, studies on energy sustainability were reviewed first, given that this study assessed the sustainability status of China's energy use. This review classifies studies into qualitative and quantitative categories, based on how they examine the overall energy sustainability situation.

\subsection{Qualitative Research on Energy Sustainability}

Scholars have completed extensive research on energy [3-26]. Researchers using qualitative approaches generally focus on the relationship between energy, policy, human, and resource factors with respect to energy sustainability.

(1) Technology: Sikdar [3] studied the sustainability of energy systems from a technical perspective, indicating that important issues need to be addressed when designing sustainable energy systems. Gupta et al. [4] noted that new technology use is critical for developing environmental sustainability; the study emphasized the importance of long-term sustainability of the global energy system for the sustainable development of the future world.

(2) Policy: Sarrica et al. [5] discussed different perspectives on sustainable energy development at different scales and illustrated the relevance and interaction between different scales of sustainable energy development topics. Lata-García et al. [7] used Ecuador's strategy as a case study to analyze relevant policies for achieving sustainable energy development. Szulecki et al. [8] analyzed the topics of energy governance and sustainable development within the European Union, recommending that energy and climate policies be streamlined to increase both energy sustainability and safety. Hess [9] examined energy and democratic social movements and studied the multiple joint viewpoints of the development of energy transformation; the study emphasized the impact of the Energy Transformation Alliance on sustainable energy development policies. Wolf [10] discussed the important role of sustainable education for sustainable energy development and reported that human resources can stimulate the promotion and application of sustainable energy technologies. Wang et al. $[11,12]$ conducted research on energy conservation policies that aim to reduce climate change without affecting economic growth. The authors suggest that clean energy use and sustainable development can be achieved.

(3) Sustainable systems: Child et al. [14] studied the development of energy sustainability protection systems; they indicated the need to introduce a boundary framework into future research on sustainable energy. Steg et al. [15] explored the factors that motivate society to participate in the transition toward sustainable energy, while also recommending options for promoting the transformation of the energy system.

(4) Interaction of different energy sources: Francesca et al. [17] used the RTD theoretical framework to study the impact of networks on the sustainable development of business models in the energy sector. Jana et al. [18] evaluated the impact of the use of organic biomaterials in India on energy sustainability and introduced biomass-based energy solutions. Parkinson et al. [19] proposed a multi-criteria analytical framework to explore both interdependencies and conflicts between sustainable development goals for water and energy.

(5) Energy efficiency and sustainability: Salvia et al. [21] used Brazil as example to investigate the challenges and opportunities for improving energy sustainability; they emphasized the importance of renewable energy. Centobelli et al. [22] studied the energy efficiency and sustainability in a supply chain context, and proposed directions for future research. Zore et al. [23] studied the impact of the 
sustainable net present value (SNPV) and highlighted the importance of renewable energy resource use as an important factor for achieving sustainable energy development.

(6) Energy projects: Popova et al. [25] proposed a system based on the structural analysis of construction projects to assess energy sustainability in urban housing. Hasheminasab et al. [26] evaluated the impact of energy infrastructure projects on sustainable development by investigating oil refining projects as a case study.

Existing research on energy sustainability has mainly focused on qualitative research and focuses on: emphasizing the important role of energy sustainability, exploring risks and challenges faced by the future development of energy, and proposing corresponding policies that promote sustainable energy development.

\subsection{Quantitative Research on Energy Sustainability}

\subsubsection{Quantitative Research Using Non-Matter-Element Extension Methods}

There have been relatively few quantitative studies addressing energy sustainability. Guen et al. [27] developed an integrated computing platform to explore the simultaneous optimization of renewable energy integration, while building renovation to improve the sustainability of rural energy. Das et al. [28] reviewed the sustainable development of water, energy, and food. They explained the challenges of sustainable development, while facing future limitations in these three resources. Dincer et al. [29] explored the dimensions of energy sustainability from a system and application perspective, emphasizing the need for sufficient sustainability assessment tools to promote sustainable energy development. Ren et al. [30] studied the important role of energy storage technology in promoting renewable energy. They established a framework for analyzing the sustainability of energy storage technologies. Noseleit [31] highlighted the important role of renewable energy technology innovation and highlighted future directions in future energy sustainability transformation. Büyüközkan et al. [32] developed a method for assessing the performance of energy projects, while interpreting the projects from a sustainable perspective.

\subsubsection{Quantitative Study Using the Matter-Element Extension Method}

Many studies have focused on energy or energy sustainability using the matter-element extension method [12,33-46]. These studies can be specifically divided into the following categories.

(1) Research on sustainability: Ren et al. [33] studied the sustainability of the hydrogen supply chain, using the matter-element extension method. Yan et al. [34] simultaneously applied the matter-element extension method and the entropy method to research the sustainability. An et al. [35] used the fuzzy analytic hierarchy process (LFPPFAHP) and the matter-element extension theory to investigate the sustainability of urban sludge treatment technology. Li et al. [37] used the matter-element extension method to evaluate the risk of development of the Qingzang Power Grid interconnection project. Ren et al. [38] established a multi-participant and multi-standard framework to sustainably assess both energy and industrial systems. The authors also researched sustainable energy development using improved matter-element extension methods.

(2) Research on energy related issues: He et al. [39] used the matter-element extension method to assess the risks associated with urban power grid planning. Li et al. [40] studied the external economics of wind power projects using both an analytic hierarchy process and matter-element extension method. They also made recommendations for promoting the sustainable development of wind power. Ranran et al. [41] used the matter-element extension analytic hierarchy process to evaluate the low-carbon operation of new energy sources and provided proposals and directions for future development. Zhaorong et al. [42] used the entropy method and the matter-element extension method to evaluate China's energy security effectively monitoring the status quo of energy security. Xingjie discussed the application of the matter-element extension method in energy demand forecasting and verified the feasibility of the method, using Xi'an as a case study. 
(3) Research on energy sustainability: Jiang et al. [45] evaluated the power quality of wind farms using an improved cloud element method. Fang et al. [46] applied the BSC method (Balanced score card) and matter-element model to study energy sustainability, evaluating the sustainability of existing wind energy projects.

The existing research has lacked a systematic review of the use of the matter-element extension method to substantially analyze energy. This research mainly focuses on: exploring energy security, determining energy project related risks, assessing energy efficiency, and predicting future energy demand.

The traditional matter-element extension method has some limitations and deficiencies and needs to be improved. When an indicator value exceeds the limited field, a correlation function value cannot be obtained; the principle of evaluation is the principle of maximum subordination, which can be subject to information loss in some cases. These disadvantages impact the accuracy of this method for sustainability studies.

Our literature review found current research in the field of energy involves many aspects, perspectives, and projects.

(1) There are many studies on the sustainable development of energy, but they mainly focus on the subjective qualitative research of policy, energy, and human factors. The qualitative research mainly focuses on the technical level and there is a lack of comprehensive systems research.

(2) There are few studies on overall sustainability, and even fewer studies on the overall sustainability of energy. In addition, few studies have assessed the changing trends of energy sustainability.

(3) The matter-element extension method has good maturity and applicability; however, the method's limitations significantly impact the objectivity of evaluation results.

To fill the gaps in existing research, this study combined the pressure-state-response (PSR) model with an improved matter-element extension method to systemically quantify China's energy sustainability. Based on the PSR model, combined with the existing research, the study established a new indicator system to comprehensively evaluate sustainable energy development. By using the combination weighting method, both the coefficient of variation and the entropy method were combined to determine the overall weight of the indicator. This expands the application scope of the combined weighting method and reduces the adverse effects of subjectively obtained factors. By using the improved matter-element extension method, this new method mitigates the challenges associated with the traditional matter-element extension method and further improves the accuracy of evaluation results.

An assessment of China's energy sustainability status from 2000 to 2015 illustrates the changing trends over time. This study recommends future sustainable development of energy and the formulation of efficient energy sustainable development policies. Accurately describing the changing trends in China's energy sustainability status provides a reference to further improve the sustainability of China's energy. Further, due to China's current energy conditions and the typical nature of its development stage, the evaluation results can provide a useful reference for other regions with similar conditions.

\section{Method and Data}

\subsection{Establishment of the Evaluation Index System}

The PSR model was developed and is widely accepted by the OECD (Organization for Economic Co-operation and Development) and UNEP (United Nations Environment Program). It has become a common method for studying environmental impact issues. The PSR model consists of pressure, status, and response metrics. The relevant stress indicators illustrate the environmental impact of human and social activities and address the question "what happened?" National indicators reflect environmental conditions and the changes due to human factors and address the question of "why 
did it happen?" These response indicators represent the remedial measures that society implements to change the environment and address the question of "what should we do?" [47]. These three issues also reflect the basic connotation of sustainable development. Therefore, this model is suitable to study sustainability issues.

Xie et al. [48] used the PSR model to analyze the impact of port construction on the surrounding environment; they constructed an evaluation index for port ecological adaptability. Yang et al. [49] constructed a PSR assessment model for the sustainable development of urban rail transit and analyzed this sustainable development with respect to three aspects: social, environmental, and economic sustainability. Shen et al. [50] applied the PSR model to urban sustainable development and identified the differences between different indicator systems. Bal-Domańska et al. [51] applied the PSR model to analyze socio-economic issues and spatio-temporal changes for sustainable development; they used the case study of Poland as a detailed example. Based on the PSR model, Ma et al. [52] constructed a comprehensive evaluation index system for sustainable forest development and evaluated the developed level of China's forest ecosystem.

Based on existing research results, this study combined factors representing reality and a state of sustainability to determine the selection criteria for relevant indicators: (1) A scientific approach, i.e., the selected indicators, should reasonably reflect the sustainable characteristics of energy. (2) Extensiveness, which involves using existing relevant research results and specific statistical methods to filter indicators commonly used by scholars. (3) Comprehensiveness, i.e., the concept of sustainability, should be considered when selecting indicators. The selected indicators should fully reflect the sustainable development status and connotation of energy. (4) Reliability considers the impact of the actual situation on the indicators and data availability when selecting the appropriate indicators. Consequently, drawing on previous studies [53-58], this study applied the above criteria to determine the index system for an evaluation of China's energy sustainability with respect to three dimensions: economy, energy and environment. Compared with the original PSR model, the index system developed in this study increases the three-dimensional levels of the energy economy, energy resources, and the environment. Based on the connotation of energy sustainability, it more effectively shows an index system of energy sustainability evaluation. See Table 1 (In Table 1, $C_{i}$ represents different indicators, $\mathrm{i}=1,2, \ldots, 20)$.

\subsection{Improved Matter-Element Extension Theory}

The traditional matter-element extension method was proposed by Wen to solve incompatent complicated problems [59]. This method simultaneously studies and evaluates an object from both qualitative and quantitative perspectives [60]. By establishing a comprehensive index system, this study clusters the relevant joint domains, classical domains, and matter elements to be evaluated. These analyses can evaluate the comprehensive characteristics of elements [61]. Xu et al. [62] used the matter-element extension method to analyze the coordination relationship between regional power grids and renewable energy sources; they also conducted an empirical study in Ningxia. Gong et al. [63] used the matter-element extension method to assess the adaptability of land development in Guangzhou, China. The method supported the analysis of local land development potentials and restrictions. Jing et al. [64] used the matter-element extension method to evaluate groundwater quality and analyzed its transformation trend. However, the principle of maximum membership associated with the traditional matter-element extension method tends to lose information, leading to bias in decision results [65]. In addition, when the indicator value exceeds the range of the joint domain, the conventional method cannot obtain the correct correlation function value. 
Table 1. Energy sustainability evaluation index system.

\begin{tabular}{|c|c|c|c|c|}
\hline Target Layer & System Layer & Dimension Layer & Indicator Layer & Index Code \\
\hline \multirow{20}{*}{$\begin{array}{c}\text { Energy Sustainability } \\
\text { Evaluation } \\
\text { Index system }\end{array}$} & \multirow{8}{*}{ Pressure } & \multirow{5}{*}{ Energy } & Total energy consumption (million tons of standard coal) & $\mathrm{C}_{1}$ \\
\hline & & & Per capita living energy consumption (kg standard coal) & $\mathrm{C}_{2}$ \\
\hline & & & Industrial energy consumption (million tons of standard coal) & $\mathrm{C}_{3}$ \\
\hline & & & Energy consumption elasticity coefficient & $\mathrm{C}_{4}$ \\
\hline & & & Electricity consumption elasticity coefficient & $\mathrm{C}_{5}$ \\
\hline & & \multirow{3}{*}{ Environment } & Total wastewater discharge (million tons) & $\mathrm{C}_{6}$ \\
\hline & & & Sulfur dioxide emissions (million tons) & $\mathrm{C}_{7}$ \\
\hline & & & Smoke and dust emissions (million tons) & $\mathrm{C}_{8}$ \\
\hline & \multirow{8}{*}{ State } & \multirow{4}{*}{ Energy } & Energy processing conversion efficiency (\%) & $\mathrm{C}_{9}$ \\
\hline & & & Million yuan of GDP energy consumption (tons of standard coal/ten thousand yuan) & $\mathrm{C}_{10}$ \\
\hline & & & Total energy production (million tons of standard coal) & $\mathrm{C}_{11}$ \\
\hline & & & Electric power production elasticity coefficient & $\mathrm{C}_{12}$ \\
\hline & & \multirow{4}{*}{ Economy } & Natural population growth rate $(\%)$ & $\mathrm{C}_{13}$ \\
\hline & & & Urbanization rate $(\%)$ & $\mathrm{C}_{14}$ \\
\hline & & & Gross domestic product (billion yuan) & $\mathrm{C}_{15}$ \\
\hline & & & GDP per capita (yuan) & $\mathrm{C}_{16}$ \\
\hline & \multirow{4}{*}{ Response } & \multirow{4}{*}{ Environment } & General industrial solid waste utilization (million tons) & $\mathrm{C}_{17}$ \\
\hline & & & Total investment in environmental pollution control (billion yuan) & $\mathrm{C}_{18}$ \\
\hline & & & Afforestation area (ha) & $\mathrm{C}_{19}$ \\
\hline & & & Industrial pollution treatment completed investment (million yuan) & $\mathrm{C}_{20}$ \\
\hline
\end{tabular}


The improved matter-element extension method overcomes the limitations of the traditional method and enables more reasonable judgments. The improved method uses similarity instead of correlation to overcome the disadvantages caused by the maximum degree of membership. In addition, the method normalizes the classic domain and to-be-evaluated matter elements, so the indicator value does not exceed the joint domain [66]. Zhang et al. [67] used the improved matter-element extension method to analyze the expansion scale of expansive soil, thus solving the problem of mutual exclusion between indicators. Deng et al. [68] used the improved matter-element extension method to evaluate river health and highlighted the method's effectiveness.

In addition, the sustainability of everything is a comprehensive concept involving the environment, economy, and society. This includes the interaction and balance between the three. The improved matter-element extension method is suitable for addressing comprehensive contradictions, and energy sustainability is a complex comprehensive issue. Therefore, it is scientific and reasonable to study energy sustainability using the improved matter-element extension method.

\subsubsection{Evaluation Criteria and Level}

The established index system was used to evaluate energy sustainability and to collect relevant data. In conjunction with the indicators included in the references, the relevant standards were adjusted appropriately. Based on the unique indicators selected for this study, levels were classified based on the underlying concept and characteristics associated with the indicators. At the same time, according to the standards of the degree of dependence of human social development on the indicator, regional economic development characteristics, and resource characteristics, this study divided the indicators in a reasonable way. Based on this, this study applied previously described methods to determine the classical domain [69] and adjusted the methods to address the actual situation, appropriately dividing the classical domain and levels.

Therefore, based on the existing literature and the real-world situation, this study divided energy sustainability into five levels: $\mathrm{N}_{1}$ indicates high efficiency (level I), $\mathrm{N}_{2}$ indicates general efficiency (level II), $\mathrm{N}_{3}$ indicates critical efficiency (Level III), $\mathrm{N}_{4}$ indicates relatively low efficiency (level IV), $\mathrm{N}_{5}$ indicates low efficiency (level V), and $\mathrm{N}_{\mathrm{p}}$ indicates the joint domain. Of these, level I indicates that energy sustainability is at its best, and its production and use will not negatively affect human society or the natural environment. This level realizes sustainable energy use. Level II indicates a general sustainability of energy sources. Energy use can meet the basic requirements of sustainable development, but energy sustainability needs further improvement. Level III indicates that energy sustainability is at a critical level; energy sustainability is very fragile and it can meet the needs of social development but this sustainability is easily disrupted. Level IV indicates that the energy sustainability is poor. Although it meets production and general living needs, it cannot meet sustainable development requirements. Level $\mathrm{V}$ indicates that the sustainability of energy sources is extremely poor. This level does not guarantee production and living needs and fails to meet sustainable development requirements. The specific levels of division are shown in Table 3.

\subsubsection{Improved Matter-Element Extension Model}

(1) The process of calculating the classical domain, the joint domain, and the matter element to be evaluated. The process used to solve the problem is included in the Appendix A of this paper.

(2) Normalization process:

$$
\mathrm{R}_{0}=\left(\mathrm{N}_{0}, \mathrm{C}_{\mathrm{i}}, \mathrm{V}_{\mathrm{i}}\right)=\left[\begin{array}{ccc}
\mathrm{N}_{0} & \mathrm{c}_{1} & \mathrm{v}_{1} \\
& \mathrm{c}_{2} & \mathrm{v}_{2} \\
& \vdots & \vdots \\
& c_{\mathrm{n}} & \mathrm{v}_{\mathrm{n}}
\end{array}\right]
$$




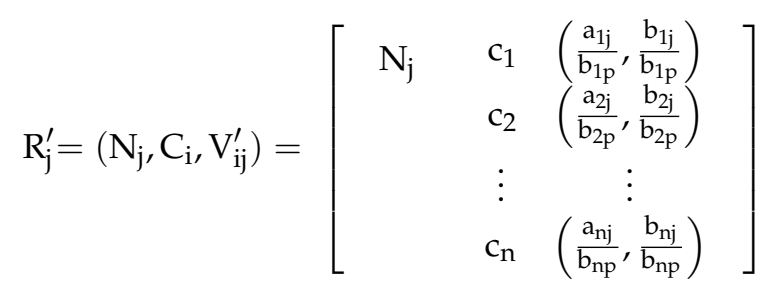

To prevent the measured values in the matter element from being evaluated by exceeding the joint domain range, we standardized the classical domain matter element and the object to be evaluated. In the formula, $R_{0}^{\prime}$ represents the normalized matter element to be evaluated; $R_{j}^{\prime}$ represents the classic domain matter element that has been normalized; and $b_{\text {ip }}$ represents the right end value of the indicator, corresponding to the node domain element (i.e., the maximum value of the indicator).

(3) Calculate the close degree:

$$
\begin{gathered}
D_{j}\left(v_{i}^{\prime}\right)=\left|v_{i}^{\prime}-\frac{a_{i j}^{\prime}+b_{i j}^{\prime}}{2}\right|-\frac{1}{2}\left(b_{i j}^{\prime}-a_{i j}^{\prime}\right) \\
N_{j}\left(R_{0}^{\prime}\right)=1-\frac{1}{n(n+1)} \sum_{i=1}^{n} D_{j}\left(v_{i}^{\prime}\right) W_{i}(X)
\end{gathered}
$$

In Equations (3) and (4), $\mathrm{n}$ represents the number of indicators, $\mathrm{W}_{\mathrm{i}}(\mathrm{X})$ represents the comprehensive weight of the indicator, $\mathrm{D}_{\mathrm{j}}\left(\mathrm{v}_{\mathrm{i}}^{\prime}\right)$ represents the distance between the matter element to be evaluated and the classical domain, and $\mathrm{N}_{\mathrm{j}}\left(\mathrm{R}_{0}^{\prime}\right)$ represents the calculated close degree.

(4) Grade judgment:

$$
\mathrm{N}_{\mathrm{m}}\left(\mathrm{R}_{0}^{\prime}\right)=\max \left[\mathrm{N}_{\mathrm{j}}\left(\mathrm{R}_{0}^{\prime}\right)\right]
$$

After calculating the close degree of each level, Equation (5) was used if the close degree of a specific level reached the maximum value. The matter element to be evaluated belonged to that level and could be determined.

(5) Calculate the eigenvalue of the comprehensive grade variable:

$$
\begin{gathered}
\overline{N_{j}}\left(R_{0}^{\prime}\right)=\frac{N_{j}\left(R_{0}^{\prime}\right)-\min \left[N_{j}\left(R_{0}^{\prime}\right)\right]}{\max \left[N_{j}\left(R_{0}^{\prime}\right)\right]-\min \left[N_{j}\left(R_{0}^{\prime}\right)\right]} \\
j^{*}=\frac{\sum_{j=1}^{m} j * \overline{N_{j}}\left(R_{0}^{\prime}\right)}{\sum_{j=1}^{m} \bar{N}_{j}\left(R_{0}^{\prime}\right)}
\end{gathered}
$$

In Equations (6) and (7), $\mathrm{j}^{*}$ represents the grading variable characteristic value of the matter element $R_{0}^{\prime}$ to be evaluated and obtained through calculation. According to Equations (6) and (7), we judged the tendency of the matter element to be evaluated from its own level to its adjacent level on both sides.

\subsection{Determination of Weight}

Determining weights is a very important part of making scientific and reasonable judgments using the improved matter-element extension method. Weights reflect the influence of different indicators on elements and determines the importance of different indicators in the system; weights also affect the process of improving the matter-element extension method and determine the correctness and accuracy of the results. Therefore, this study used both the entropy method and the coefficient of variation method to determine the weights. Then, a combination weighting method was used to combine and determine the comprehensive weights. This expanded the scope of application of the combined weighting method, and improved the weight accuracy. 


\subsubsection{Entropy Method to Determine Weights}

The entropy method is an objective weighting method that uses entropy to measure indicator weights. Entropy is a concept from physics and is generally used to denote disorder. The entropy method introduces the concept of entropy into systems research. Based on the degree of variation in each index, each index's entropy weight is calculated using information entropy. Then, the index weight is revised by using the entropy weight, thereby objectively obtaining the index weight. A larger entropy value of the index indicates a higher degree of disorder; consequently, the smaller the effect, the less weight the index has [70]. Zou et al. [71] proposed a new method for evaluating entropy weight and applied this method to assess water quality. Islam et al. [72] used the entropy method to determine the weight of the parameters and to assess groundwater quality in a specific area of Bangladesh. Liu et al. [73] used the entropy method to determine the index weight and the DEA (Data Envelopment Analysis) model to evaluate the construction level and investment efficiency of public infrastructure.

The specific weight calculation process is as follows:

(1) Dimensionless processing data

(1) Forward processing of the reverse index:

$$
\mathrm{X}_{\mathrm{ki}}=\left(\mathrm{V}_{\mathrm{ki}}\right)_{\max }-\mathrm{V}_{\mathrm{ki}}
$$

In Equation (8), $V_{k i}$ represents the raw data of the $k^{\text {th }}$ reverse index at year $i$ and $X_{k i}$ represents the data after forward processing.

(2) Dimensionless treatment of all indicators:

$$
\mathrm{Y}_{\mathrm{ki}}=\frac{\mathrm{X}_{\mathrm{ki}}}{\sum_{\mathrm{i}=1}^{\mathrm{n}} \mathrm{X}_{\mathrm{ki}}}
$$

In Equation (9), $\mathrm{Y}_{\mathrm{ki}}$ represents the non-dimensionalized data of the $\mathrm{k}^{\text {th }}$ index at year $\mathrm{i}$; and $\mathrm{X}_{\mathrm{ki}}$ represents the data of the raw index (forward index) before processing, or the data of the index (reverse index) that has undergone forward processing, where $\mathrm{i}=1,2, \ldots, \mathrm{n}$ and $\mathrm{k}=1,2, \ldots, \mathrm{m}$.

(2) Calculation of entropy:

$$
\begin{gathered}
\mathrm{f}_{\mathrm{ik}}=\frac{1+\mathrm{y}_{\mathrm{ki}}}{\sum_{\mathrm{k}=1}^{\mathrm{s}}\left(1+\mathrm{y}_{\mathrm{ki}}\right)} \\
\mathrm{t}=-\frac{1}{\ln \mathrm{k}} \\
\mathrm{H}_{\mathrm{i}}=-\mathrm{t} \sum_{\mathrm{k}=1}^{\mathrm{s}} \mathrm{f}_{\mathrm{ik}} \ln \mathrm{f}_{\mathrm{ik}}
\end{gathered}
$$

In Equations (10)-(12), $\mathrm{H}_{\mathrm{i}}$ represents the index's entropy, where $\mathrm{i}=1,2, \ldots, \mathrm{n}$ and $\mathrm{k}=1,2, \ldots, \mathrm{m}$.

(3) Calculation of Weights:

$$
\mathrm{W}_{\mathrm{i}}=\frac{1-\mathrm{H}_{\mathrm{i}}}{\mathrm{n}-\sum_{\mathrm{i}=1}^{\mathrm{n}} \mathrm{H}_{\mathrm{i}}}
$$

In Equation (13), $W_{i}$ indicates the weight of the index, where $i=1,2, \ldots, n$.

\subsubsection{Coefficient of Variation Method to Determine Weights}

The coefficient of variation method is an objective and dynamic weighting method that uses the degree of variation in the indicator data. The greater the change in indicators, the greater the importance of the indicators in the evaluation system. Therefore, the indicator is assigned a higher weight. The coefficient of variation method is an objective weighting method; the empowerment process does not need to artificially determine the relevant influencing factors. Mathematical reasoning can be used to derive the corresponding index weights, reducing the influence of subjective factors $[74,75]$. 
Li et al. [76] applied the coefficient of the variation method to calculate the indicator weights and established a bidding evaluation model for power engineering projects. Li et al. [77] used the coefficient of the variation method to establish a reliability analysis model for smart substation systems and instance applications. Zhao et al. [78] used the coefficient of variation method to determine the weights of corresponding indicators and used this to assess the groundwater quality.

The specific weight calculation process is as follows:

(1) Non-dimensionalized raw data

Forward index:

$$
X_{i j}^{\prime}=\frac{X_{i j}-\min _{i}\left[X_{i j}\right]}{\max _{i}\left[X_{i j}\right]-\min _{i}\left[X_{i j}\right]}
$$

Reverse index:

$$
X_{i j}^{\prime}=\frac{\max _{i}\left[X_{i j}\right]-X_{i j}}{\max _{i}\left[X_{i j}\right]-\min _{i}\left[X_{i j}\right]}
$$

In Equations (14) and (15), $X_{\mathrm{ij}}^{\prime}$ represents the dimensionless data of the $\mathrm{j}^{\text {th }}$ index in year $\mathrm{i}$; and $\mathrm{X}_{\mathrm{ij}}$ represents raw data, where $i=1,2, \ldots, n$ and $j=1,2, \ldots, m$.

(2) Calculate the mean value and standard deviation:

$$
\begin{gathered}
\overline{\mathrm{c}_{j}}=\frac{1}{n_{i=1}} \sum_{\mathrm{ij}}^{\mathrm{n}} \mathrm{X}^{\prime} \\
\mathrm{s}_{\mathrm{j}}=\sqrt{\frac{\sum_{\mathrm{i}=1}^{\mathrm{n}}\left(\mathrm{X}_{\mathrm{ij}}^{\prime}-\overline{\mathrm{C}_{\mathrm{j}}}\right)^{2}}{\mathrm{n}-1}}
\end{gathered}
$$

In Equations (16) and (17), $\overline{\mathrm{c}_{\mathrm{j}}}$ represents the mean value of the $\mathrm{j}^{\text {th }}$ indicator; and $\mathrm{s}_{\mathrm{j}}$ represents the standard deviation of the $j^{\text {th }}$ indicator, where $j=1,2, \ldots, m$.

(3) Calculation of coefficient of variation:

$$
\mathrm{v}_{\mathrm{j}}=\frac{\mathrm{s}_{\mathrm{j}}}{\overline{\overline{\mathrm{c}_{\mathrm{j}}}}}[\mathrm{j}=1,2, \ldots, \mathrm{m}]
$$

In Equation (18), $v_{j}$ represents the coefficient of variation of the indicator, where $j=1,2, \ldots, m$.

(4) Calculate weights:

$$
w_{j}=\frac{v_{j}}{\sum_{i=1}^{n} v_{j}}[j=1,2, \ldots, m]
$$

In Equation (19), $w_{j}$ indicates the weight of the index, where $j=1,2, \ldots, m$.

\subsubsection{Combination Weighting Method to Determine the Comprehensive Weight}

Generally, the combined weighting method combines the weights obtained by subjective and objective weighting methods to obtain the comprehensive weights $[11,79,80]$. However, there is no unified system for evaluating energy sustainability. Scholars often begin with their own subjective perspective and apply different indicators. However, obtaining weights using subjective judgment lacks rationality. Because of this, this study expanded the scope of the application of the combination weighting method and used this method to combine objective weighting methods to obtain comprehensive weights. An entropy weight method is vulnerable to the influence of quantity when there are many indicators. The coefficient of variation method directly uses internal data connections, mitigating challenges with the entropy weight method. This reduces the impact of human factors as much as possible, generating a more scientific and reasonable evaluation result. 
The specific weight calculation process is as follows:

$$
\mathrm{w}_{0}=\frac{w_{\mathrm{i}}^{1} \mathrm{w}_{\mathrm{i}}^{2}}{\sum_{\mathrm{i}=1}^{\mathrm{n}} \mathrm{w}_{\mathrm{i}}^{1} \mathrm{w}_{\mathrm{i}}^{2}}
$$

In Equation (20), $\mathrm{w}_{0}$ represents the comprehensive weights obtained using the combination weighing method, $w_{\mathrm{i}}^{1}$ represents the weight determined using the first method, and $\mathrm{w}_{\mathrm{i}}^{2}$ represents the weight determined using the second method, where $i=1,2, \ldots, n$.

\section{Results}

Using China as a case study, this study applied the improved matter-element extension model to evaluate China's energy sustainability. This allowed for the identification of existing problems, and provides recommendations for future development.

\subsection{Indicator System and Determination of Weights}

Past research and the analysis above was used to establish an evaluation index system, as shown in Table 1. Using this established index system, the corresponding data [81] from 2000-2015 for China were collected and used. The results of the specific gravity calculation are shown in Table 2.

Table 2. Index Weight.

\begin{tabular}{cccc}
\hline Index & $\mathbf{W}_{1}$ (Entropy Method) & $\mathbf{W}_{2}$ (Coefficient of Variation Method) & $\mathbf{W}_{0}$ (Comprehensive Weight) \\
\hline $\mathbf{C}_{1}$ & 0.049995 & 0.058552 & 0.058547 \\
$\mathbf{C}_{2}$ & 0.049999 & 0.046929 & 0.046928 \\
$\mathbf{C}_{3}$ & 0.049997 & 0.053148 & 0.053145 \\
$\mathbf{C}_{4}$ & 0.050001 & 0.035261 & 0.035262 \\
$\mathbf{C}_{5}$ & 0.049998 & 0.049120 & 0.049119 \\
$\mathbf{C}_{6}$ & 0.049998 & 0.048491 & 0.048489 \\
$\mathbf{C}_{7}$ & 0.050000 & 0.040329 & 0.040329 \\
$\mathbf{C}_{8}$ & 0.049999 & 0.047525 & 0.047524 \\
$\mathbf{C}_{9}$ & 0.050004 & 0.046461 & 0.046466 \\
$\mathbf{C}_{10}$ & 0.049996 & 0.055397 & 0.055393 \\
$\mathbf{C}_{11}$ & 0.050003 & 0.048565 & 0.048568 \\
$\mathbf{C}_{12}$ & 0.050003 & 0.040891 & 0.040893 \\
$\mathbf{C}_{13}$ & 0.050002 & 0.031072 & 0.031073 \\
$\mathbf{C}_{14}$ & 0.050004 & 0.046799 & 0.046803 \\
$\mathbf{C}_{15}$ & 0.049999 & 0.065271 & 0.065270 \\
$\mathbf{C}_{16}$ & 0.049999 & 0.064727 & 0.064726 \\
$\mathbf{C}_{17}$ & 0.050000 & 0.056239 & 0.056240 \\
$\mathbf{C}_{18}$ & 0.049998 & 0.065582 & 0.065579 \\
$\mathbf{C}_{19}$ & 0.050003 & 0.039984 & 0.039987 \\
$\mathbf{C}_{20}$ & 0.050001 & 0.059658 & 0.059659 \\
\hline
\end{tabular}

Raw data from China Statistical Yearbook [81].

According to Table 2, the main factors impacting sustainable energy development in China were the total investment in environmental pollution control, gross domestic product (GDP), GDP per capita, and completed investments in industrial pollution treatment.

\subsection{Level of Division}

According to the classical domain determination method published above, when considering the actual situation in China, energy sustainability can be divided into five levels. See Table 3 for details. 
Table 3. Energy sustainability level.

\begin{tabular}{cccccccccccccc}
\hline Index & \multicolumn{2}{c}{$\mathbf{N}_{1}$} & \multicolumn{2}{c}{$\mathbf{N}_{2}$} & \multicolumn{2}{c}{$\mathbf{N}_{3}$} & \multicolumn{2}{c}{$\mathbf{N}_{4}$} & $\mathbf{N}_{5}$ & \multicolumn{2}{c}{$\mathbf{N}_{\mathbf{p}}$} \\
\hline $\mathbf{C}_{1}$ & $(0$ & $0.2843)$ & $(0.2843$ & $0.4633)$ & $(0.4633$ & $0.6422)$ & $(0.6422$ & $0.8211)$ & $(0.8211$ & $1)$ & $(0$ & $1)$ \\
$\mathbf{C}_{2}$ & $(0$ & $0.3235)$ & $(0.3235$ & $0.4926)$ & $(0.4926$ & $0.6617)$ & $(0.6617$ & $0.8309)$ & $(0.8309$ & $1)$ & $(0$ & $1)$ \\
$\mathbf{C}_{3}$ & $(0$ & $0.2603)$ & $(0.2603$ & $0.4452)$ & $(0.4452$ & $0.6301)$ & $(0.6301$ & $0.8151)$ & $(0.8151$ & $1)$ & $(0$ & $1)$ \\
$\mathbf{C}_{4}$ & $(0$ & $0.0615)$ & $(0.0615$ & $0.2961)$ & $(0.2961$ & $0.5307)$ & $(0.5307$ & $0.7654)$ & $(0.7654$ & $1)$ & $(0$ & $1)$ \\
$\mathbf{C}_{5}$ & $(0$ & $0.3064)$ & $(0.3064$ & $0.4798)$ & $(0.4798$ & $0.6532)$ & $(0.6532$ & $0.8266)$ & $(0.8266$ & $1)$ & $(0$ & $1)$ \\
$\mathbf{C}_{6}$ & $(0$ & $0.5129)$ & $(0.5129$ & $0.6347)$ & $(0.6347$ & $0.7565)$ & $(0.7565$ & $0.8782)$ & $(0.8782$ & $1)$ & $(0$ & $1)$ \\
$\mathbf{C}_{7}$ & $(0$ & $0.6928)$ & $(0.6928$ & $0.7696)$ & $(0.7696$ & $0.8464)$ & $(0.8464$ & $0.9232)$ & $(0.9232$ & $1)$ & $(0$ & $1)$ \\
$\mathbf{C}_{8}$ & $(0$ & $0.4723)$ & $(0.4723$ & $0.6042)$ & $(0.6042$ & $0.7361)$ & $(0.7361$ & $0.8681)$ & $(0.8681$ & $1)$ & $(0$ & $1)$ \\
$\mathbf{C}_{9}$ & $(1$ & $0.9808)$ & $(0.9808$ & $0.9615)$ & $(0.9615$ & $0.9423)$ & $(0.9423$ & $0.9231)$ & $(0.9231$ & $0)$ & $(0$ & $1)$ \\
$\mathbf{C}_{10}$ & $(0$ & $0.3788)$ & $(0.3788$ & $0.5341)$ & $(0.5341$ & $0.6894)$ & $(0.6894$ & $0.8447)$ & $(0.8447$ & $1)$ & $(0$ & $1)$ \\
$\mathbf{C}_{11}$ & $(1$ & $0.8321)$ & $(0.8321$ & $0.6642)$ & $(0.6642$ & $0.4963)$ & $(0.4963$ & $0.3284)$ & $(0.3284$ & $0)$ & $(0$ & $1)$ \\
$\mathbf{C}_{12}$ & $(1$ & $0.8225)$ & $(0.8225$ & $0.6451)$ & $(0.6451$ & $0.4676)$ & $(0.4676$ & $0.2901)$ & $(0.2901$ & $0)$ & $(0$ & $1)$ \\
$\mathbf{C}_{13}$ & $(0$ & $0.5778)$ & $(0.5778$ & $0.6834)$ & $(0.6834$ & $0.7889)$ & $(0.7889$ & $0.8945)$ & $(0.8945$ & $1)$ & $(0$ & $1)$ \\
$\mathbf{C}_{14}$ & $(1$ & $0.9021)$ & $(0.9021$ & $0.8042)$ & $(0.8042$ & $0.7063)$ & $(0.7063$ & $0.6085)$ & $(0.6085$ & $0)$ & $(0$ & $1)$ \\
$\mathbf{C}_{15}$ & $(1$ & $0.7686)$ & $(0.7686$ & $0.5371)$ & $(0.5371$ & $0.3057)$ & $(0.3057$ & $0.0743)$ & $(0.0743$ & $0)$ & $(0$ & $1)$ \\
$\mathbf{C}_{16}$ & $(1$ & $0.7668)$ & $(0.7668$ & $0.5336)$ & $(0.5336$ & $0.3003)$ & $(0.3003$ & $0.0671)$ & $(0.0671$ & $0)$ & $(0$ & $1)$ \\
$\mathbf{C}_{17}$ & $(1$ & $0.7762)$ & $(0.7762$ & $0.5523)$ & $(0.5523$ & $0.3285)$ & $(0.3285$ & $0.1046)$ & $(0.1046$ & $0)$ & $(0$ & $1)$ \\
$\mathbf{C}_{18}$ & $(1$ & $0.7987)$ & $(0.7987$ & $0.5975)$ & $(0.5975$ & $0.3962)$ & $(0.3962$ & $0.1949)$ & $(0.1949$ & $0)$ & $(0$ & $1)$ \\
$\mathbf{C}_{19}$ & $(1$ & $0.8364)$ & $(0.8364$ & $0.6727)$ & $(0.6727$ & $0.5091)$ & $(0.5091$ & $0.3454)$ & $(0.3454$ & $0)$ & $(0$ & $1)$ \\
$\mathbf{C}_{20}$ & $(1$ & $0.7815)$ & $(0.7815$ & $0.5631)$ & $(0.5631$ & $0.3446)$ & $(0.3446$ & $0.1262)$ & $(0.1262$ & $0)$ & $(0$ & $1)$ \\
\hline
\end{tabular}

\subsection{Establishment of Classical Domains, Joint Domains, and the Matter Element to Be Evaluated}

Based on the improved matter-element extension method described above, we established the corresponding classical domain, joint domain matter elements, and matter elements to be evaluated. At the same time, to analyze the changes in energy sustainability over a specific period of time, this study established the matter elements for an annual evaluation from 2000 to 2015. Details are as follows:

(1) Create the classic domain matter element:

Table 3 shows the range of different levels of indicators forming the classic domain:

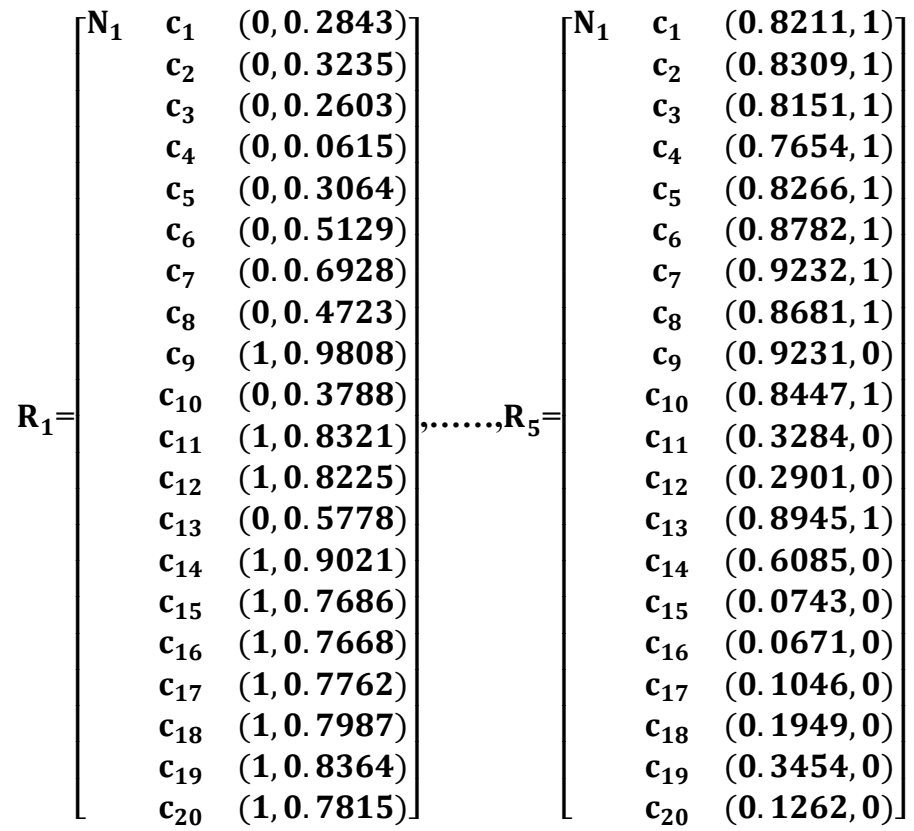

The same can be obtained for $R_{1}, R_{2}, R_{3}, R_{4}$ and $R_{5}$. 
(2) Create the joint domain matter element:

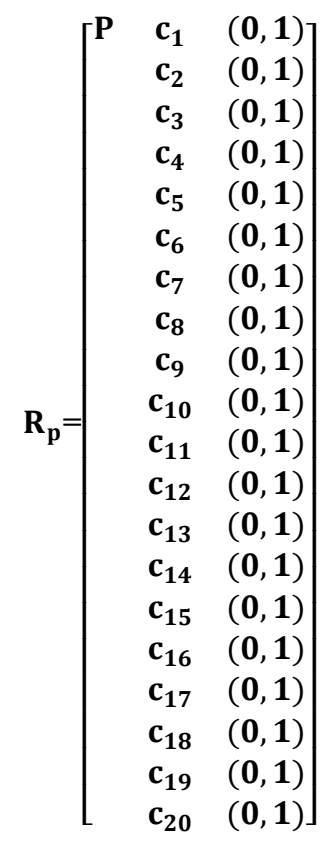

(3) Create the matter element to be evaluated:

\begin{tabular}{|c|c|c|c|c|c|c|}
\hline & {$\left[\mathrm{N}_{0}\right.$} & $\left.c_{1} \quad 0.2687\right]$ & & {$\left[\mathbf{N}_{\mathbf{0}}\right.$} & $c_{1}$ & 0.7859 \\
\hline & & $c_{2} \quad 0.3086$ & & & $c_{2}$ & 0.8542 \\
\hline & & $c_{3} \quad 0.2491$ & & & $c_{3}$ & 0.8123 \\
\hline & & $c_{4} \quad 0.3053$ & & & $\mathbf{c}_{4}$ & 0.0792 \\
\hline & & $c_{5} \quad 0.6142$ & & & $c_{5}$ & 0.2303 \\
\hline & & $c_{6} \quad 0.5064$ & & & $c_{6}$ & 0.8973 \\
\hline & & $c_{7} \quad 0.7398$ & & & $c_{7}$ & 0.6894 \\
\hline & & $c_{8} \quad 0.8863$ & & & $c_{8}$ & 0.6039 \\
\hline & & $c_{9} \quad 0.9250$ & & & $c_{9}$ & 0.9788 \\
\hline & & $10 \quad 0.7486$ & & & $c_{10}$ & 0.3616 \\
\hline & & 1110.3071 & ...., & & $c_{11}$ & 0.8011 \\
\hline & & $12 \quad 0.5995$ & & & $\mathrm{c}_{12}$ & 0.2268 \\
\hline & & $13 \quad 1.0024$ & & & $c_{13}$ & 0.6559 \\
\hline & & $14 \quad 0.5884$ & & & $c_{14}$ & 0.9113 \\
\hline & & $15 \quad 0.1241$ & & & $c_{15}$ & 0.8527 \\
\hline & & $16 \quad 0.1298$ & & & $c_{16}$ & 0.8213 \\
\hline & & $17 \quad 0.1356$ & & & $c_{17}$ & 0.7196 \\
\hline & & $18 \quad 0.0644$ & & & $c_{18}$ & 0.5585 \\
\hline & & $19 \quad 0.5285$ & & & $\mathbf{c}_{19}$ & 0.7954 \\
\hline & & $200.2247]$ & & & & $0.7403]$ \\
\hline
\end{tabular}

Of these, $R_{2000}$ represents the object to be evaluated in the year 2000 (using the value after standardization); the same can be obtained for different years: $R_{2000}, R_{2001}, R_{2002}, \ldots \ldots, R_{2015}$.

4.4. Calculate the Close Degree, Judge the Grade, and Obtain the Eigenvalue of the Comprehensive Grade Variable

Based on the above, the closeness of the matter element to be evaluated, $R_{2000}-R_{2015}$ was sequentially calculated. Equation (5) was used to determine the energy sustainability level of the matter element. Equations (6) and (7) were used to determine the eigenvalue of the comprehensive grade variable. The specific calculation results are shown in Table 4 . 
Table 4. Close degree and eigenvalue of the grade variable.

\begin{tabular}{lccccccc}
\hline $\begin{array}{c}\text { Close Degree the Matter } \\
\text { Element to Be Evaluated }\end{array}$ & $\mathbf{N}_{1}$ & $\mathbf{N}_{2}$ & $\mathbf{N}_{3}$ & $\mathbf{N}_{4}$ & $\mathbf{N}_{5}$ & Level & $\begin{array}{c}\text { The Eigenvalue of the } \\
\text { Comprehensive Grade } \\
\text { Variable }\end{array}$ \\
\hline $\mathbf{N}_{\mathbf{j}}\left(\mathbf{R}_{2000}\right)$ & 0.99896 & 0.99927 & 0.99947 & 0.99956 & 0.99924 & IV & 3.50251 \\
$\mathbf{N}_{\mathbf{j}}\left(\mathbf{R}_{2001}\right)$ & 0.99897 & 0.99929 & 0.99950 & 0.99959 & 0.99924 & IV & 3.48260 \\
$\mathbf{N}_{\mathbf{j}}\left(\mathbf{R}_{2002}\right)$ & 0.99899 & 0.99932 & 0.99949 & 0.99961 & 0.99922 & IV & 3.43871 \\
$\mathbf{N}_{\mathbf{j}}\left(\mathbf{R}_{2003}\right)$ & 0.99896 & 0.99929 & 0.99946 & 0.99961 & 0.99924 & IV & 3.50232 \\
$\mathbf{N}_{\mathbf{j}}\left(\mathbf{R}_{2004}\right)$ & 0.99894 & 0.99932 & 0.99956 & 0.99966 & 0.99927 & IV & 3.48535 \\
$\mathbf{N}_{\mathbf{j}}\left(\mathbf{R}_{2005}\right)$ & 0.99895 & 0.99935 & 0.99966 & 0.99970 & 0.99926 & IV & 3.44560 \\
$\mathbf{N}_{\mathbf{j}}\left(\mathbf{R}_{2006}\right)$ & 0.99901 & 0.99941 & 0.99975 & 0.99965 & 0.99921 & III & 3.32442 \\
$\mathbf{N}_{\mathbf{j}}\left(\mathbf{R}_{2007}\right)$ & 0.99908 & 0.99948 & 0.99983 & 0.99962 & 0.99913 & III & 3.14169 \\
$\mathbf{N}_{\mathbf{j}}\left(\mathbf{R}_{2008}\right)$ & 0.99916 & 0.99954 & 0.99981 & 0.99956 & 0.99905 & III & 2.89031 \\
$\mathbf{N}_{\mathbf{j}}\left(\mathbf{R}_{2009}\right)$ & 0.99917 & 0.99957 & 0.99981 & 0.99956 & 0.99904 & III & 2.86389 \\
$\mathbf{N}_{\mathbf{j}}\left(\mathbf{R}_{2010}\right)$ & 0.99920 & 0.99960 & 0.99978 & 0.99953 & 0.99901 & III & 2.77952 \\
$\mathbf{N}_{\mathbf{j}}\left(\mathbf{R}_{2011}\right)$ & 0.99926 & 0.99964 & 0.99969 & 0.99948 & 0.99895 & III & 2.65814 \\
$\mathbf{N}_{\mathbf{j}}\left(\mathbf{R}_{2012}\right)$ & 0.99931 & 0.99966 & 0.99963 & 0.99942 & 0.99890 & II & 2.55927 \\
$\mathbf{N}_{\mathbf{j}}\left(\mathbf{R}_{2013}\right)$ & 0.99938 & 0.99963 & 0.99954 & 0.99932 & 0.99884 & II & 2.44622 \\
$\mathbf{N}_{\mathbf{j}}\left(\mathbf{R}_{2014}\right)$ & 0.99939 & 0.99956 & 0.99945 & 0.99925 & 0.99881 & II & 2.39510 \\
$\mathbf{N}_{\mathbf{j}}\left(\mathbf{R}_{2015}\right)$ & 0.99942 & 0.99955 & 0.99941 & 0.99921 & 0.99879 & II & 2.33696 \\
\hline
\end{tabular}

According to Table 4:

China's energy sustainability efficiency was at level IV between 2000 and 2005. As a result, its energy sustainability was less efficient. According to the principle of maximum posting progress, from 2000 to 2005, the largest level was level III. This shows that the sustainability of China's energy rose for those five years.

China's energy sustainability efficiency was at level III from 2006 to 2011, and its sustainability efficiency was at critical efficiency. However, from 2006 to 2008, the sustainability of China's energy declined. The status improved over the next three years.

In 2015, China's energy sustainability was at level II, but it tended to enter level I. China's energy development has entered a new stage.

The Table 4 shows the composite eigenvalues of the different matter-level variables evaluated. These are the corresponding composite eigenvalues for different years. The time series changes are reflected in the form of a line graph (Figure 1).

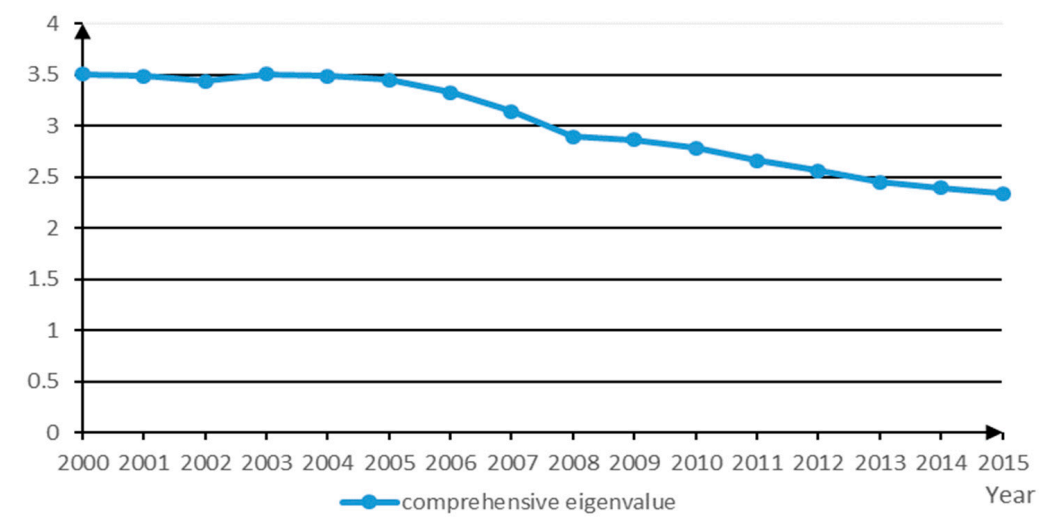

Figure 1. The curve of the eigenvalue of the comprehensive grade variable.

Figure 1 shows that during this time period, the comprehensive characteristic values experienced a steady downward trend, i.e., the energy sustainability efficiency steadily increased.

\section{Analysis and Discussion}

(1) According to Table 2, total investment in environmental pollution control, gross domestic product (GDP), GDP per capita, industrial pollution treatment completed investment, and total energy consumption have significantly impacted China's energy sustainability. The total investment in 
environmental pollution control shows that China's attitude towards environmental protection impacts energy development planning. The GDP is an indicator for China's level of economic development and serves as the basis for the developing energy economy. The total energy consumption shows China's demand for energy in development. The results of this study's calculations provide insights that can guide relevant departments in adjusting and planning the energy plan. The study also provides a new perspective for the sustainable development of energy in China. Energy development cannot be separated from peoples' needs; however, the sustainable development of energy should be based on the principle of environmental protection while also meet the growing energy needs of the people by promoting economic levels.

(2) The calculation in Table 2 shows that combining both objective weighting methods, by using the combination weighting method, expands the scope of application for the combination weighting method. Further, the method of entropy weight and coefficient of variation complement each other. Reducing the influence of subjective human factors can improve the accuracy of the evaluation results. This yields a more reasonable index weight covering the three dimensions of the environment, energy, and economy. It also shows that the development of energy involves the mutual promotion and interaction of energy, economy, and environment. Rationally coordinating these three relationships can better realize the sustainable development of energy.

(3) Figure 1 shows that during this time period, the eigenvalues of China's energy comprehensive grades experienced an initial decrease, followed by rising and falling trends. The year 2002 was the lowest point of the comprehensive eigenvalue during the study period. This may be related to changes in energy intensity. Huang et al. [82] conducted a panel data assessment, finding that China's energy intensity first declined and then increased from 2001 to 2003; the intensity was highest in 2005. This is consistent with the results of this study. Sun et al. used the exponential decomposition method to determine that China's energy intensity experienced an upward trend from 2000 to 2005, indicating that the efficiency of energy use decreased during this time [83]. This may have led to a decline in energy sustainability. However, it may also be the result of the energy policy adopted by the government at this stage. The changes in the curve indicate that energy sustainability initially attracted widespread attention, with people emphasizing effective energy use. However, later implementation of energy policies has been unsatisfactory, resulting in a decline in the efficiency of energy sustainability. This may be due to the lack of oversight during the later period, a lack of effective evaluation tools, or poor implementation of local government policies.

(4) Figure 1 shows that the efficiency status of energy sustainability underwent significant changes from 2000-2015. Specifically, from 2000-2015, the state of energy sustainability experienced fluctuations, with unsatisfactory efficiency levels. During this period, China focused more on economic development, paying inadequate attention to the sustainable use of energy and environmental protection. Energy use was extensive and the heavy use of coal placed tremendous pressure on the environment. Energy was used solely for economic development purposes and did not account for the environmental costs incurred.

From 2006-2011, the efficiency of energy sustainability began to increase, starting with relatively low efficiency and shifting toward critical efficiency. In this period, China began to recognize the importance of sustainable development, changed its approach to energy use, and enhanced public awareness of the importance of environmental protection and sustainable development. However, during this time, the efficiency of energy sustainability remained unstable and faced a risk of decline. This indicated that energy sustainability needed further improvements. From 2012-2015, the efficiency of energy sustainability reached a good general level of efficiency.

Generally, China's concept of sustainable development is deeply rooted in people's consciousness and is gaining public recognition. China's developmental approach has begun to change with the goal of protecting and improving efficiency, with a goal of achieving good and rapid development. The transformation of energy use modes has reduced coal use and has promoted clean energy. Energy structure adjustments have begun, and it has been proposed that in 2030, the proportion of non-fossil 
energy to renewable energy in China will account for $20 \%$. China has attached great importance to the ecological environment and has implemented relevant laws and regulations to ensure that sustainable development is further improved. However, there remains a gap between the current sustainable energy efficiency and the optimal situation. As such, energy use should be further improved. In the future, energy utilization needs to focus on sustainable development and there needs to be continued improvements in the efficiency of sustainable energy use.

\section{Conclusions}

The sustainable development of energy is connected to the survival of human society. China is currently the largest developing country in the world. Its development is in a steady growth stage, and its development model has begun to transform. This study combined the PSR model and an improved matter element extension method to quantify the China's energy sustainability from 2000 to 2015.

(1) This study developed a comprehensive sustainable energy evaluation index based in the three dimensions of energy, economy, and environment and using the PSR model. This evaluation system absorbed the findings of existing research, and fully integrates the connotation of energy sustainability, thereby reflecting energy sustainability characteristics.

(2) An improved matter-element extension method was applied and introduced to China's energy sustainability efficiency evaluation process. The method mitigates the limitations of the traditional matter-element method. China's energy sustainability can be evaluated by establishing the classical domain, the joint domain, and the object to be evaluated. The calculation results are consistent with the real-world situation, reflecting sustainable development and changes in China's energy utilization.

(3) The study calculated and analyzed the efficiency of China's energy sustainability from 2000 to 2015. China's energy sustainability status improved from 2000 to 2015 but remained at a low level. This was because the use of high-carbon fossil energy still accounted for the majority of China's energy consumption. Therefore, the transformation in the economic growth mode was far from meeting sustainable development requirements.

(4) The study calculated the general situation and influencing factors of China's energy sustainable development. However, research challenges remain. For example, the construction of the indicator system was not comprehensive enough. In addition, the study was able to determine the degree of influence for a single factor, but could not establish the comprehensive influence of energy, economy, or the environment on the system. Therefore, future research will focus on building a more comprehensive and reasonable index system. This will allow for the further analysis of the impact of energy, economy, and environment on energy sustainability.

The incompatibility of different sectors with regard to sustainable energy use and their protection has hindered further improvements in the sustainable efficiency of energy. The economic costs of developing clean energy and protecting the environment are unacceptably high. This makes it important to further mitigate the disadvantages of relevant policies. More effort is needed to achieve harmony between sustainable energy use and stable economic growth.

Author Contributions: R.L. conceived and designed the experiments and wrote the paper; S.L performed the experiments and analyzed the data. All authors read and approved the final manuscript.

Funding: This research is founded by National Natural Science Foundation of China (Grant No. 71874203), Shandong Provincial Natural Science Foundation, China (Grant No. ZR2018MG016), the Ministry of Education of Humanities and Social Science Project, China (Grant No. 18YJA790081), and the Fundamental Research Funds for the Central Universities (18CX04009B).

Conflicts of Interest: The authors declare no conflict of interest.

\section{Appendix A The Classical Domain, the Joint Domain, and the Matter Element to Be Evaluated}

(1) Classic domain matter element:

In the equation (1), $R_{j}$ represents a classical domain matter element. This indicates the corresponding value range of each indicator when the sustainability of energy is located at a certain 
level. Furthermore, $N_{j}$ indicates that the classical domain is at the $j^{\text {th }}$ level, $C_{i}$ represents the $i^{\text {th }}$ index, $V_{i j}$ represents the value range of the $i^{t h}$ index in the j-level, and $a_{i j}$ and $b_{i j}$ represent the starting and ending values of the utilized range.

(2) Joint domain matter element:

In Equation (2), $R_{p}$ represents the joint domain matter matter element. This characterizes the union of the classic domain matter elements, the overall range of $V_{i p}$ represents the entire range of values for the $i^{\text {th }}$ indicator, and $\left(a_{1 p}, b_{1 p}\right)$ represent the specific values of the range.

(3) The matter element to be evaluated:

In Equation (3), $R_{0}$ represents the matter element to be evaluated. This is a feature set of all elements that need to be evaluated, $N_{0}$ represents the level of the object to be evaluated, and $V_{I}$ represents the measured value of the $i^{\text {th }}$ feature.

\section{References}

1. State Council Information Office of China. China's Energy Conditions and Policies; State Council Information Office of China: Beijing, China, 2017.

2. Wang, Q.; Su, M.; Li, R. Toward to economic growth without emission growth: The role of urbanization and industrialization in China and India. J. Clean. Prod. 2018, 205, 499-511. [CrossRef]

3. Sikdar, S.K. Sustainability of Energy Systems: Views from Technology Perspectives; Springer: Singapore, 2018.

4. Gupta, J.G.; De, S.; Gautam, A.; Dhar, A.; Pandey, A. Introduction to Sustainable Energy, Transportation Technologies, and Policy; Springer: Singapore, 2018.

5. Sarrica, M.; Biddau, F.; Brondi, S.; Cottone, P.; Mazzara, B.M. A multi-scale examination of public discourse on energy sustainability in Italy: Empirical evidence and policy implications. Energy Policy 2018, 114, 444-454. [CrossRef]

6. Wang, Q.; Li, S.; Li, R.; Ma, M. Forecasting U.S. shale gas monthly production using a hybrid ARIMA and metabolic nonlinear grey model. Energy 2018, 160, 378-387. [CrossRef]

7. Lata-García, J.; Reyes-Lopez, C.; Jurado, F. Attaining the energy sustainability: Analysis of the Ecuadorian strategy. Probl. Ekorozwoju 2018, 13, 21-29.

8. Szulecki, K.; Westphal, K. Taking Security Seriously in EU Energy Governance: Crimean Shock and the Energy Union; Palgrave Macmillan: Cham, Switzerland, 2018.

9. Hess, D.J. Energy democracy and social movements: A multi-coalition perspective on the politics of sustainability transitions. Energy Res. Soc. Sci. 2018, 40, 177-189. [CrossRef]

10. Wolf, F.; Curran, F.; Pflaum, E.; Ramic, H. Education for Sustainability: Integrating Climate Change and Energy into Lifelong Learning Initiatives for Small Island Developing States; Springer: Cham, Switzerland, 2018.

11. Wang, Q.; Chen, X. Energy policies for managing China's carbon emission. Renew. Sustain. Energy Rev. 2015, 50, 470-479. [CrossRef]

12. Wang, Q.; Li, R. Journey to burning half of global coal: Trajectory and drivers of China's coal use. Renew. Sustain. Energy Rev. 2016, 58, 341-346. [CrossRef]

13. Bilgen, S.; Sarıaya, İ. Energy conservation policy and environment for a clean and sustainable energy future. Energy Sources Part B Econ. Plan. Policy 2018, 13, 1-7. [CrossRef]

14. Child, M.; Koskinen, O.; Linnanen, L.; Breyer, C. Sustainability guardrails for energy scenarios of the global energy transition. Renew. Sustain. Energy Rev. 2018, 91, 321-334. [CrossRef]

15. Steg, L.; Shwom, R.; Dietz, T. What Drives Energy Consumers? Engaging People in a Sustainable Energy Transition. IEEE Power Energy Mag. 2018, 16, 20-28. [CrossRef]

16. Wang, Q.; Zhao, M.; Li, R.; Su, M. Decomposition and decoupling analysis of carbon emissions from economic growth: A comparative study of China and the United States of America. J. Clean. Prod. 2018, 197, 178-184. [CrossRef]

17. Francesca, R.; Andrea, L. Network impact on business models for sustainability: Case study in the energy sector. J. Clean. Prod. 2018, 182, 694-704.

18. Jana, K.; Mahanta, P.; De, S. Role of Biomass for Sustainable Energy Solution in India. In Sustainable Energy and Transportation; Springer: Singapore, 2018. 
19. Parkinson, S.C.; Makowski, M.; Krey, V.; Sedraoui, K.; Almasoud, A.H.; Djilali, N. A multi-criteria model analysis framework for assessing integrated water-energy system transformation pathways. Appl. Energy 2017, 210, 477-486. [CrossRef]

20. Wang, Q.; Zhao, M.; Li, R. Decoupling sectoral economic output from carbon emissions on city level: A comparative study of Beijing and Shanghai, China. J. Clean. Prod. 2019, 209, 126-133. [CrossRef]

21. Salvia, A.L.; Brandli, L.L.; Frandoloso, M.A.L. Prerequisites for Energy Sustainability in Municipalities in Rio Grande do Sul, Brazil. In Lifelong Learning and Education in Healthy and Sustainable Cities; Springer: Cham, Switzerland, 2018.

22. Centobelli, P.; Cerchione, R.; Esposito, E. Environmental Sustainability and Energy-Efficient Supply Chain Management: A Review of Research Trends and Proposed Guidelines. Energies 2018, 11, 275. [CrossRef]

23. Zore, Ž.; Čuček, L.; Širovnik, D.; Pintarič, Z.N.; Kravanja, Z. Maximizing the Sustainability Net Present Value of Renewable Energy Supply Networks. Chem. Eng. Res. Des. 2018, 131, 245-265. [CrossRef]

24. Wang, Q.; Li, R. Decline in China's coal consumption: An evidence of peak coal or a temporary blip? Energy Policy 2017, 108, 696-701. [CrossRef]

25. Popova, O.; Glebova, J.; Karakozova, I. Complex Assessment of Urban Housing Energy Sustainability. E3S Web Conf. 2018, 33, 02041. [CrossRef]

26. Hasheminasab, H.; Gholipour, Y.; Kharrazi, M.; Streimikiene, D. A Novel Metric of Sustainability for Petroleum Refinery Projects. J. Clean. Prod. 2017, 171, 1215-1224. [CrossRef]

27. Guen, M.L.; Mosca, L.; Perera, A.T.D.; Coccolo, S.; Mohajeri, N.; Scartezzini, J.L. Improving the energy sustainability of a Swiss village through building renovation and renewable energy integration. Energy Build. 2018, 158, 906-923. [CrossRef]

28. Das, T.; Cabezas, H. Tools and concepts for environmental sustainability in the food-energy-water nexus: Chemical engineering perspective. Environ. Prog. Sustain. Energy 2018, 37, 73-81. [CrossRef]

29. Dincer, I.; Zamfirescu, C. Exergetic, Energetic and Environmental Dimensions; Academic Press: Cambridge, MA, USA, 2018; pp. 101-152.

30. Ren, J.; Ren, X.; Ren, J.; Ren, X.; Ren, J.; Ren, X. Sustainability Ranking of Energy Storage Technologies under Uncertainties. J. Clean. Prod. 2018, 170, 1387-1398. [CrossRef]

31. Noseleit, F. Renewable energy innovations and sustainability transition: How relevant are spatial spillovers? J. Reg. Sci. 2017, 58, 259-275. [CrossRef]

32. Büyüközkan, G.; Karabulut, Y. Energy project performance evaluation with sustainability perspective. Energy 2017, 119, 549-560. [CrossRef]

33. Ren, J.; Manzardo, A.; Toniolo, S.; Scipioni, A. Sustainability of hydrogen supply chain. Part II: Prioritizing and classifying the sustainability of hydrogen supply chains based on the combination of extension theory and AHP. Int. J. Hydrogen Energy 2013, 38, 13845-13855. [CrossRef]

34. Yan, J.; Feng, C.; Li, L. Sustainability assessment of machining process based on extension theory and entropy weight approach. Int. J. Adv. Manuf. Technol. 2014, 71, 1419-1431. [CrossRef]

35. An, D.; Xi, B.; Ren, J.; Ren, X.; Zhang, W.; Wang, Y.; Dong, L. Multi-criteria sustainability assessment of urban sludge treatment technologies: Method and case study. Resour. Conserv. Recycl. 2018, 128, 546-554. [CrossRef]

36. Wang, Q.; Li, S.; Li, R. China's dependency on foreign oil will exceed 80\% by 2030: Developing a novel NMGM-ARIMA to forecast China's foreign oil dependence from two dimensions. Energy 2018, 163, 151-167. [CrossRef]

37. Li, C.; Liu, Y.; Li, S. Risk Evaluation of Qinghai-Tibet Power Grid Interconnection Project for Sustainability. Sustainability 2016, 8, 85. [CrossRef]

38. Ren, J.; Ren, X.; Liang, H.; Dong, L.; Zhang, L.; Luo, X.; Yang, Y.; Gao, Z. Multi-actor multi-criteria sustainability assessment framework for energy and industrial systems in life cycle perspective under uncertainties. Part 2: Improved extension theory. Int. J. Life Cycle Assess. 2017, 22, 1406-1417. [CrossRef]

39. He, Y.X.; Dai, A.Y.; Zhu, J.; He, H.Y.; Li, F. Risk assessment of urban network planning in china based on the matter-element model and extension analysis. Int. J. Electr. Power Energy Syst. 2011, 33, 775-782. [CrossRef]

40. Li, H.; Guo, S. External Economies Evaluation of Wind Power Engineering Project Based on Analytic Hierarchy Process and Matter-Element Extension Model. Math. Probl. Eng. 2014, 2013, 848901. [CrossRef]

41. Yan, H.; Wu, J.; Yan, H.; Liu, X. Extension Evaluation Method for Low-carbon and High-efficiency Operation of New Energy Distribution Network. J. Electr. Eng. 2018, 2, 15-23. 
42. Chen, Z.; Lei, X. Entropy-based extension based energy security assessment model in China. Syst. Eng. 2015, 1, 153-158.

43. Wang, Q.; Li, S.; Li, R. Forecasting energy demand in China and India: Using single-linear, hybrid-linear, and non-linear time series forecast techniques. Energy 2018, 161, 821-831. [CrossRef]

44. Yu, X.; Chang, J.; Huang, Q.; Wang, Y. Application of Extension Analysis in Energy Demand Forecasting. Water Resour. Power 2007, 25, 154-156.

45. Jiang, H.; Zhang, Q.; Peng, J. An improved cloud matter element model based wind farm power quality evaluation. Power Syst. Technol. 2014, 38, 205-210.

46. Fang, F.; Yu, A. Sustainability Assess of Wind Energy Project Based on Improved BSC-Hierarchy Model; Springer: Berlin/Heidelberg, Germany, 2012; pp. 435-441.

47. Xu, H.; Zhou, L.; Cheng, Q. Study on ecosystem health evaluation and risk assessment for Linghekou wetlands based on a PSR model. Acta Ecol. Sin. 2017, 37, 8264-8274.

48. Xie, Y.; Xia, L.V.; Liu, R.; Mao, L.; Liu, X. Research on port ecological suitability evaluation index system and evaluation model. Front. Struct. Civ. Eng. 2015, 9, 65-70. [CrossRef]

49. Yang, Z.; Chen, X. Evaluation of Urban Rail Transit Sustainable Development Based on the PSR Model. In Proceedings of the Cota International Conference of Transportation Professionals, Shanghai, China, 6-9 July 2016; pp. 1941-1950.

50. Shen, L.; Zhou, J. Examining the effectiveness of indicators for guiding sustainable urbanization in China. Habitat Int. 2014, 44, 111-120. [CrossRef]

51. Bal-Domańska, B. Spatial-Temporal Analysis of Selected Socio-Economic Problems Related to Sustainable Development in the Pressure-State-Response Framework. Electr. Eng. 2017, 2, 92-110. [CrossRef]

52. Ma, B.; Zheng, Z.; Wen, Y. Forest Ecosystem Sustainable Development Evaluation and Prediction Based on PSR Model. Adv. J. Food Sci. Technol. 2016, 11, 158-163.

53. Miao, R.; Zhou, F.; Hu, X.; Feng, S.; Wu, D.; Jia, R. Research on Comprehensive Evaluation of Sustainable Development of Energy in China. China Soft Sci. 2013, 9, 17-25.

54. Li, G.; Li, Y.; Jia, X.; Du, L.; Huag, D. Construction and Simulation of System Dynamics Model for Water-Energy-Food Sustainable Development in Beijing. Manag. Rev. 2016, 28, 11-26.

55. Wang, Q.; Li, S.; Li, R. Will Trump's coal revival plan work?-Comparison of results based on the optimal combined forecasting technique and an extended IPAT forecasting technique. Energy 2019, 169, 762-775. [CrossRef]

56. Xiao, R.; Dong, Z.; Li, X.; Dong, J. The System Dynamics Model of Energy Sustainable Development in Xinjiang. Manag. Rev. 2014, 26, 31-41.

57. Miao, R.; Wang, L.; Wu, D.; Hu, X.; Zhou, F. Construction of China Energy Sustainable Development Evaluation Index System and Preliminary Evaluation. Energy China 2012, 34, 22-27.

58. Afgan, N.H.; Carvalho, M.G.; Hovanov, N.V. Energy system assessment with sustainability indicators. Energy Policy 2000, 28, 603-612. [CrossRef]

59. Cai, W. Extension theory and its application. Chin. Sci. Bull. 1999, 44, 673-682. [CrossRef]

60. Wang, Q.; Chen, X.; Jha, A.N.; Rogers, H. Natural gas from shale formation-The evolution, evidences and challenges of shale gas revolution in United States. Renew. Sustain. Energy Rev. 2014, 30, 1-28. [CrossRef]

61. Yu, D.; Zhang, B.; Xu, C. Application of the improved extension evaluation method based on entropy weight in groundwater quality evaluation. J. Shenyang Jianzhu Univ. 2017, 1, 127-133.

62. Xu, X.; Niu, D.; Qiu, J.; Wu, M.; Wang, P.; Qian, W.; Jin, X. Comprehensive Evaluation of Coordination Development for Regional Power Grid and Renewable Energy Power Supply Based on Improved Matter Element Extension and TOPSIS Method for Sustainability. Sustainability 2016, 8, 143. [CrossRef]

63. Gong, J.; Liu, Y.; Chen, W. Land suitability evaluation for development using a matter-element model: A case study in Zengcheng, Guangzhou, China. Land Use Policy 2012, 29, 464-472. [CrossRef]

64. Jing, J.; Hui, Q.; Yu, C. Assessment of Groundwater Quality Based on Matter Element Extension Model. J. Chem. 2012, 2013, 715647. [CrossRef]

65. Wang, Q.; Li, R. Research status of shale gas: A review. Renew. Sustain. Energy Rev. 2017, 74, 715-720. [CrossRef]

66. Liu, S.; Zhang, J.; He, Z.; Cai, D.; Tian, G. Application of improved matter-element extension model to typhoon disaster pre-assessment. J. Nat. Disasters 2012, 2, 135-141. 
67. Zhang, H.Y.; Zeng, J.M. Improvement of matter-element extension model and its application to classification of expansive soils. Rock Soil Mech. 2008, 29, 1681-1684.

68. Deng, X.; Xu, Y.; Han, L.; Yu, Z.; Yang, M.; Pan, G. Assessment of river health based on an improved entropy-based fuzzy matter-element model in the Taihu Plain, China. Ecol. Indic. 2015, 57, 85-95. [CrossRef]

69. Zhang, J.; Zhang, J.; Li, C.; Wang, S. The Method of Determining Classical Domain with the Extension Pattern Recognition Algorithm. J. Nav. Aeronaut. Astronaut. Univ. 2015, 1, 87-90.

70. Yan, Z.; Li, J. Evaluation of Giant Panda Distribution System Based on Entropy Method and Variation Coefficient. Chin. J. Appl. Ecol. 2017, 28, 4007-4016.

71. Zou, Z.; Sun, J. Study and Application on the Entropy method for Determination of Weight of evaluating indicators in Fuzzy Synthetic Evaluation for Water Quality Assessment. Acta Sci. Circumstant. 2005, 44, 171-202.

72. Islam, A.; Ahmed, N.; Bodruddoza, M.; Chu, R. Characterizing groundwater quality ranks for drinking purposes in Sylhet district, Bangladesh, using entropy method, spatial autocorrelation index, and geostatistics. Environ. Sci. Pollut. Res. Int. 2017, 24, 26350-26374. [CrossRef]

73. Liu, Q.; Wang, S.; Zhang, W.; Li, J.; Zhao, Y.; Li, W. China's municipal public infrastructure: Estimating construction levels and investment efficiency using the entropy method and a DEA model. Habitat Int. 2017, 64, 59-70. [CrossRef]

74. Wang, Q.; Li, S.; He, G.; Li, R.; Wang, X. Evaluating sustainability of water-energy-food (WEF) nexus using an improved matter-element extension model: A case study of China. J. Clean. Prod. 2018, 202, 1097-1106. [CrossRef]

75. Wang, Q.; Chen, X.; Xu, Y.-C. Accident like the Fukushima unlikely in a country with effective nuclear regulation: Literature review and proposed guidelines. Renew. Sustain. Energy Rev. 2013, 17, 126-146. [CrossRef]

76. Li, W.; Dong, W.D.; Yuan, Y.N.; Wang, D. Application of coefficient of variation and osculating value method in bidding evaluation of power construction project. In Proceedings of the 2009 International Conference on Future BioMedical Information Engineering, Sanya, China, 13-14 December 2009; pp. 529-531.

77. Li, Z.; Li, W.; Li, H.; Yu, K.; Zhao, H.; Lin, X. A reliability evaluation model for intelligent substation secondary system based on variation coefficient method. In Proceedings of the 5th International Conference on Electric Utility Deregulation and Restructuring and Power Technologies, Changsha, China, 26-29 November 2015; pp. 2360-2364.

78. Zhao, W.; Lin, J.; Wang, S.F.; Liu, J.L.; Chen, Z.R.; Kou, W.J. Influence of Human Activities on Groundwater Environment Based on Coefficient Variation Method. Environ. Sci. 2013, 34, 1277-1283.

79. Sun, X.; Niu, J.; Gong, Q.; Li, Z. A Web Service Selection Strategy Based on Combination Weighting. Appl. Res. Comput. 2017, 34, 2408-2411.

80. Pan, J.; Meng, L.; Zhong, Z. The Method of Quadratic Combination Weighting Fuzzy Comprehensive Evaluation applied in Water Quality Assessment. ICMAEE 2014, 57, 127-130.

81. National Bureau of Statistics. China Statistical Yearbook; China Statistics Press: Beijing, China, 2016.

82. Huang, J.; Hao, Y.; Lei, H. Indigenous versus foreign innovation and energy intensity in China. Renew. Sustain. Energy Rev. 2017, 81, 1721-1729. [CrossRef]

83. Sun, Y.; Li, Q.; Chen, T. Analysis of Industry Differences and Influencing Factors of China's Energy Consumption Intensity-Based on Exponential Decomposition. World Surv. Res. 2016, 4, $28-34$.

(C) 2019 by the authors. Licensee MDPI, Basel, Switzerland. This article is an open access article distributed under the terms and conditions of the Creative Commons Attribution (CC BY) license (http://creativecommons.org/licenses/by/4.0/). 